\title{
Enterovesical Fistula, CTCAE
}

National Cancer Institute

\section{Source}

National Cancer Institute. Enterovesical Fistula, CT CAE. NCI Thesaurus. Code C143446.

A disorder characterized by an abnormal communication between the urinary bladder and the intestine. 